\title{
DISPLACEMENT FIELD AROUND AN UPLIFTING INNOVATED PLATE ANCHOR
}

\author{
Mohsen SABERMAHANI * and Mehrzad Shojaee NASIRABADI
}

School of Civil Engineering, Iran University of Science and Technology, Narmak, Tehran, Iran

*Corresponding author's e-mail: msabermahani@iust.ac.ir

\begin{tabular}{l}
\hline ARTICLE INFO \\
\hline Article history: \\
Received 16 November 2019 \\
Accepted 1 February 2020 \\
Available online 14 February 2020
\end{tabular}

Keywords:

Anchor plate

Pullout capacity

Sand deformation zone

PIV

Opening anchor plate

\begin{abstract}
This paper introduces an innovated plate anchor, increasing its bearing section area during uplift. In this experimental study, the influences of embedment depth of plate anchor and soil surface condition (restricted or free) on sand deformation field during uplift test are investigated. In order to study the soil deformation around the anchor, Particle Image Velocimetry (PIV) is used. The experimental setup consists of a camera, a new designed box, load cell, encoder and computer. During the uplift test on physical models, images are captured and used by PIV to depict the soil displacement field. Based on this study, it is found that pullout capacity and sand deformation zone are significantly influenced by anchor embedment depth. In shallow anchors, sand deformation zone lines are similar to a curve and cross the soil surface; however, in deep anchors, sand deformation zone is a bulb-shaped zone that extends from anchor to a distance of approximately two times its diameter above.

Soil surface restriction increases anchor pullout capacity in shallow anchors up to $37 \%$, but in deep ones, there is no significant difference. Soil surface restriction changes shallow anchor behavior to deep anchors; however, it has no notable influence on deep anchors.
\end{abstract}

\section{INTRODUCTION}

Anchors are light structure members that are used to support structures such as transmission towers, anchored bulkheads, submerged pipelines, offshore floating platforms against uplift forces (Ilamparuthi et al., 2002). Pullout capacity of anchors (P), define as maximum pullout load carried by anchor, depends on various factors, such as type, shape, size, depth and inclination of the anchor, embedment depth and subsoil condition. Therefore, the required pullout capacity of plate anchor systems can be enhanced by increasing the size and embedment depth of the anchor or improving backfill strength and density (Ganesh and Sahoo, 2016; Kumar and Bhoi, 2009; Liu et al., 2011; Rahimi, et al., 2018).

Nowadays a wide variety of anchor systems including mechanical anchors (plate anchors, helical anchors, deadman anchors, pile anchors, and drag anchors), grouted anchors and their combination have been used and improved (Das and Shukla, 2013; Sabatini et al., 1999). One of the most applicable anchors that are implemented to resist uplift forces for light structures is mechanical plate anchors. A review on vital parameters and their influence on plate anchor pullout capacity is summarized in Table 1.

The pullout capacity of a plate anchor typically includes the weight of soil within the failure zone as well as frictional and/or cohesive resistance along the considered failure surface.
In order to understand the behavior of a plate anchor and estimating its pullout capacity, perceiving soil failure mechanism in the vicinity of uplifted plate anchor is necessary. Various failure surfaces have been proposed by many researchers such as (1) frictional cylinder method (Majer, 1955), (2) truncated cone with different apex angles (MacDonald, 1963; Mors, 1959; Veesaert and Clemence, 1977); (3) circular failure surface (Baker and Konder, 1966; Ball, 1961), (4) punching shear (Mariupol'skii, 1965), (5) logarithmic spiral failure surface (Matsuo, 1968; Rhadilkar, Parad et al., 1971), (6) truncated pyramidal shape (Meyerhof and Adams, 1968) and (7) exponential failure surface (Chattopadhyay and Pise, 1986). A brief description of each failure surface is proposed in Table 2 .

Moreover, the failure mechanism around anchor plate subjected to uplift loading has been investigated recently using Image Processing Techniques (Duan et al., 2018; Liu et al., 2011).

Despite numerous researches performed to recognize anchor failure surface, considerable differences are observed between estimated models and actual measurements that can be due to a lack of full understanding of interaction between anchor and surrounding soil and also inattention to all test steps and focus only on final failure surface.

An experimental investigation of soil deformation around a new invented anchor plate during uplift in sand by using Particle Image velocimetry (PIV) is presented in this paper. The proposed study includes 
Table 1 Vital parameters and their influence on plate anchor pullout capacity.

\begin{tabular}{|c|c|}
\hline Variable & $\begin{array}{l}\text { Important effects on horizontal pullout capacity (P) or breakout factor } \\
\qquad\left(N_{q}\right)^{*}\end{array}$ \\
\hline $\begin{array}{l}\text { Embedment ratio** }(\mathrm{R}=\mathrm{H} / \mathrm{B}) \\
\text { (depth of embedment/anchor } \\
\text { width) }\end{array}$ & $\begin{array}{l}\text { 1- Anchor pullout capacity increases as embedment ratio increases (Ball, } \\
\text { 1961; Dickin and Laman, 2007; Dickin, 1988, 1994; Frydman and Shaham, } \\
\text { 1989; Keskin, 2015; Krishnaswamy and Parashar, 1994; Murray and Geddes, } \\
\text { 1989; Rowe and Davis, 1982; Sakai and Tanaka, 1998; Sergeev and } \\
\text { Savchenko, 1972). } \\
\text { 2- Rate of pullout capacity increase due to embedment ratio increase is greater } \\
\text { in dense sand rather than loose sand (Dickin and Laman, 2007; Krishnaswamy } \\
\text { and Parashar, 1994; Murray and Geddes, 1989; Rowe and Davis, 1982; } \\
\text { Sergeev and Savchenko, 1972). }\end{array}$ \\
\hline Scale effect & $\begin{array}{l}\text { Scale effect is more remarkable in pullout capacity as embedment ratio } \\
\text { increase (Sakai and Tanaka, 1998). }\end{array}$ \\
\hline Anchor shape and geometry & $\begin{array}{l}\text { 1- Breakout factor values for circular plates are, on average, approximately } \\
1.26 \text { times those of square plates for H/square width=H/circle diameter } \\
\text { (Murray and Geddes, 1989). } \\
\text { 2- As aspect ratio*** (L/B) increases, anchor pullout capacity increases, but } \\
\text { breakout factor decreases (Dickin, 1988). } \\
\text { 3- No significant difference between pipe and strip anchor pullout capacities } \\
\text { (with the same width) in variation of embedment ratios is observed (Dickin, } \\
\text { 1994). }\end{array}$ \\
\hline Anchor size & $\begin{array}{l}\text { 1-Anchor size influence on breakout factor is greater for square anchors rather } \\
\text { than rectangular anchors (Dickin, 1988). } \\
2 \text { - Increment in anchor size leads to pullout capacity increment and breakout } \\
\text { factor reduction. The proposed effect is more remarkable in square shapes } \\
\text { rather than rectangular shapes (Dickin, 1988). }\end{array}$ \\
\hline Anchor roughness & $\begin{array}{l}\text { 1-Anchor roughness has a negligible effect on ultimate capacity of horizontal } \\
\text { anchors at all depths (Rowe and Davis, 1982). } \\
\text { CONTRADICTION: The proposed point is in contradiction with Murray and } \\
\text { Geddes (1987) results for roughened plates in dense sand, while have a good } \\
\text { agreement for medium dense soils with no dilatancy (Murray and Geddes, } \\
\text { 1989). }\end{array}$ \\
\hline \multicolumn{2}{|c|}{ 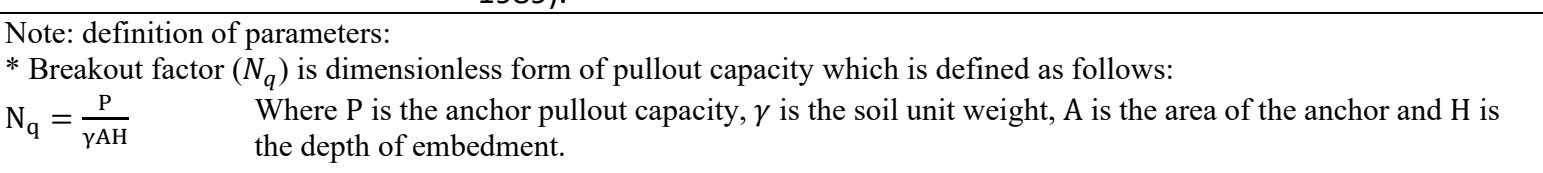 } \\
\hline
\end{tabular}

series of scaled model tests to study the effect of embedment depth and soil surface restriction on soil deformation field around the anchor; therefore it can improve the understanding of interaction between soil and anchor and leads to predict a precise failure surface especially for new invented anchors.

\section{IMAGE PROCESSING TECHNIQUE PIV DESCRIPTION}

Particle image velocimetry (PIV) is a technique developed in the 1980s to observe the global instantaneous displacement of fluids. Since soil deformation caused by landslides, earthquakes, piles penetration, etc. can be regarded as slow fluid motion, PIV technique is proposed to study soil deformation in geotechnical engineering by White et al. (2003).

A PIV system consists of three parts: tracer particles, image capture system and image processing system, shown in Figure 1 (Duan et al., 2018).

\section{TRACER PARTICLES}

In this study, the soil particles are used as tracer particles. In order to increase the accuracy of the image processing, colored soil layers were employed. Moreover, number of magnets, moving on test box glass was used as tracer particles additionally.

\section{IMAGE CAPTURE SYSTEM}

A digital camera was used to capture images. Since the corresponding particles need to be found in two adjacent images, the camera and the test box and consequently test area were relatively static. Specific added markers on the glass that do not move with the soil particles were used to convert the image displacement to the actual displacement.

\section{IMAGE PROCESSING SYSTEM}

The image processing system proposed by White et al. (2003) was implemented in this study. 
Table 2 A brief description of different failure surface.

\begin{tabular}{lll}
\hline Failure surface shape & Researchers & Description \\
\hline & & - The pullout capacity is equal to the weight of soil within the cylindrical
\end{tabular}

(1) Frictional cylinder -Major (1955) failure surface located above the anchor and the frictional resistance along this surface.

- Several researchers have reported this method to be conservative.

- Mors (1959) considered a truncated cone above the anchor with an apex angle of $90+\varphi$.

- The pullout capacity is equal to the weight of the soil within the truncated

-Mors (1959) cone. Frictional resistance acting along the failure surface was ignored.

$\begin{array}{lll} & \text {-Macdonald } & \text { - Mors' method is usually conservative for shallow anchors but over } \\ \text { (2) Truncated cone } & \text { (1963) } & \text { predicts pullout capacity for deeper anchors. } \\ & \text {-Veesaret and } & \text {-Macdonald (1963) assumed an inclined truncated cone and cylindrical } \\ & \text { Clemence (1977) } & \text { failure surface for shallow anchors and deep anchors, respectively. }\end{array}$

Clemence (1977) - Clemence and Veesaert (1977) assumed an inverted truncated cone as

failure surface, with an apex angle of $\varphi$, extending upwards from the anchor base. The pullout capacity was computed from the weight of soil within this cone and the shearing resistance along the failure surface.

- Balla (1961) observed a vertical rupture surface at the upper surface of the circular plate anchor, crossing the ground surface at angle of approximately $45^{\circ}-\varphi / 2$. - Balla simplified this surface to a circular arc

(3) Circular failure surface
-Balla (1961)

-Baker and

Kondner (1966) with radius $(H-t) / \sin \left(45^{\circ}+\varphi / 2\right)$.

- It was reported that ultimate pullout capacity of the anchor is the sum of soil weight in the failure zone and shearing resistance developed along the failure surface.

- A similar surface was observed by Baker and Kondner (1966) for anchors with $H / B<6$.

- Mariupol'skii (1965) described deep anchor behavior as tunneling through the soil (punching shear) and assumed that ultimate pullout capacity is the sum of anchor weight and loads transmitted to the soil by its plate and stem.

For shallow anchors, Mariupol'skii (1965) observed the failure surface as

(4) Punching shear

-Mariupol'skii

(1965)

-Vesic (1965) a truncated cone with a slightly convex generatrix and with an angle at the apex close to $90^{\circ}$, but considered the generatrix of the cone to be rectilinear.

- For shallow anchors, the ultimate pullout capacity is computed from anchor weight, soil weight and total shear resistance along the lateral surface of the separated cone.

-Vesic (1965) also observed punching shear failure surface for deep anchors.

- Matsuo (1967) considered the rupture surface to a logarithmic spiral surface, crossing the soil surface at the angle of $45^{\circ}-\varphi / 2$.

(5) Logarithmic spiral failure surface

-Matsuo (1967)

-Rhadilkar et al. (1971)

- Rhadilkar et al. (1971) also assumed a logarithmic spiral rupture surface and developed an analysis using Kotter's equation for the shearing resistance along the curved surface. Murray and Geddes (1987) commented that their analysis does not produce frictional resistance forces on the failure surface in the required direction and is thus invalid.

- At the ultimate uplift load a soil mass having an approximately truncated pyramidal shape is lifted up and, for shallow footing depths, the failure surface reaches the ground surface, while for deep anchors, the compressibility and deformation of the soil mass above the footing prevent the failure surface from reaching the ground surface.

(6) Truncated Meyerhof and pyramidal shape Adam (1968)

- For shallow anchors, failure surface in soil makes an angle of $90^{\circ}-\varphi / 3$ to $90^{\circ}-2 \varphi / 3$ with an average of about $90^{\circ}-\varphi / 2$ with the horizontal.

-The magnitude of the proposed angle $\square$ depends on several factors, such as the relative density of compaction and the angle of internal friction of the soil.

Chattopadhyay and Pise (1986) assumed an exponential equation for the failure surface. The shape and extent of the failure surface depend on the

(7) Exponential failure surface
- Chattopadhyay and Pise (1986) slenderness ratio, the angle of shearing resistance of the soil, and anchor friction angle.

-The failure surface equation satisfied the boundary conditions proposed by Balla (1961) and Meyerhof and Adams (1968). 


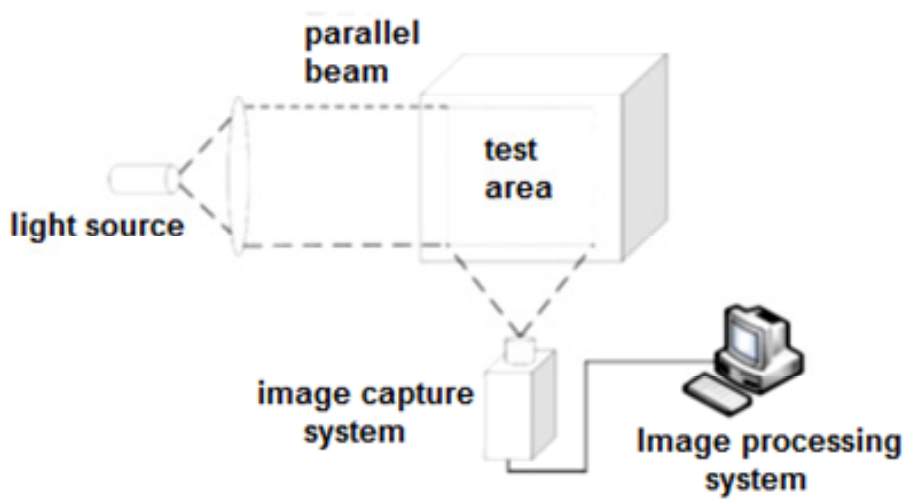

Fig. 1 Schematic diagram of PIV system (Duan et al., 2018).

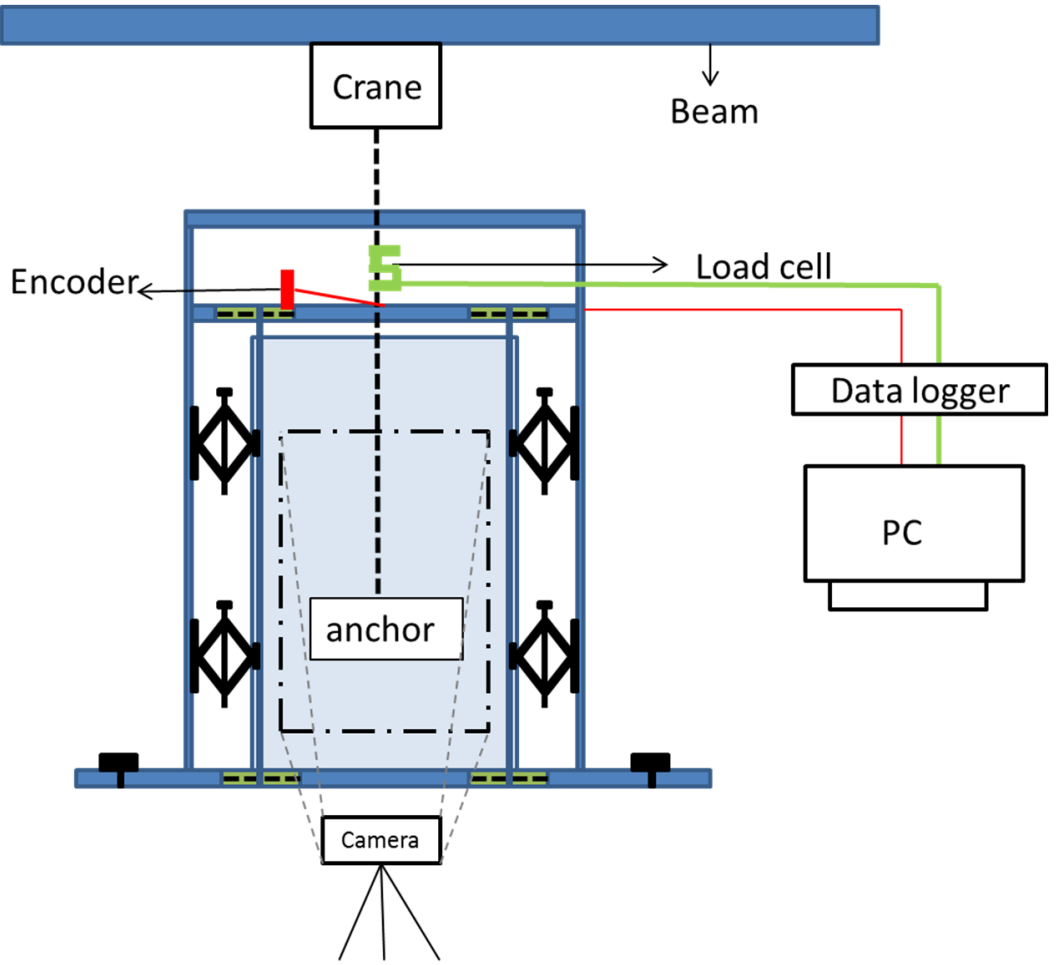

Fig. 2 Schematic experimental setup.

\section{EXPERIMENTAL SETUP AND TEST PROCEDURE}

The experimental setup in this research consists of a camera, Plane strain box, load cell, linear encoder and computer, as shown in Figure 2. The camera had $4 \mathrm{~K}$ resolution and located in a dark room in order to eliminate the light reflects. The load cell with a loading capacity of $10 \mathrm{kN}$ was hanged of a beam in laboratory. The data acquisition system was used to process the signals measured by digital instruments and transform them to load and displacement data.

\section{PLANE STRAIN BOX}

For the proposed study, a new type of box with width of $1.6 \mathrm{~m}$, height of $1.8 \mathrm{~m}$, outer thickness of $0.1 \mathrm{~m}$ and inner thickness of $0.08 \mathrm{~m}$ is designed and built. Small thickness of the box in comparison with its other dimensions helps to observe sand deformation field and anchor movements clearly.
Two narrow side walls of the box are made of steel and two faces (wider sides) are made of unbreakable thick glass, therefore displacement field can be observed from both faces and with more clarity than plexiglas. $10 \mathrm{~mm}$ thickness of glasses helps them to perform as rigid bodies and banned deformations. In order to provide the zero shear stress between the soil and glass side walls, silicone grease was used; therefore plane strain mode is simulated. Plane strain box is shown in Figure $3 a$ and Figure $3 b$. The box base is bolted to the ground and does not move during the uplift test.

In order to investigate the effect of lateral initial forces condition in future researches, four jacks are located on two sides of the steel frame. Opening the jacks leads to decrease the width of the container by sliding the side walls on top and down rails. 

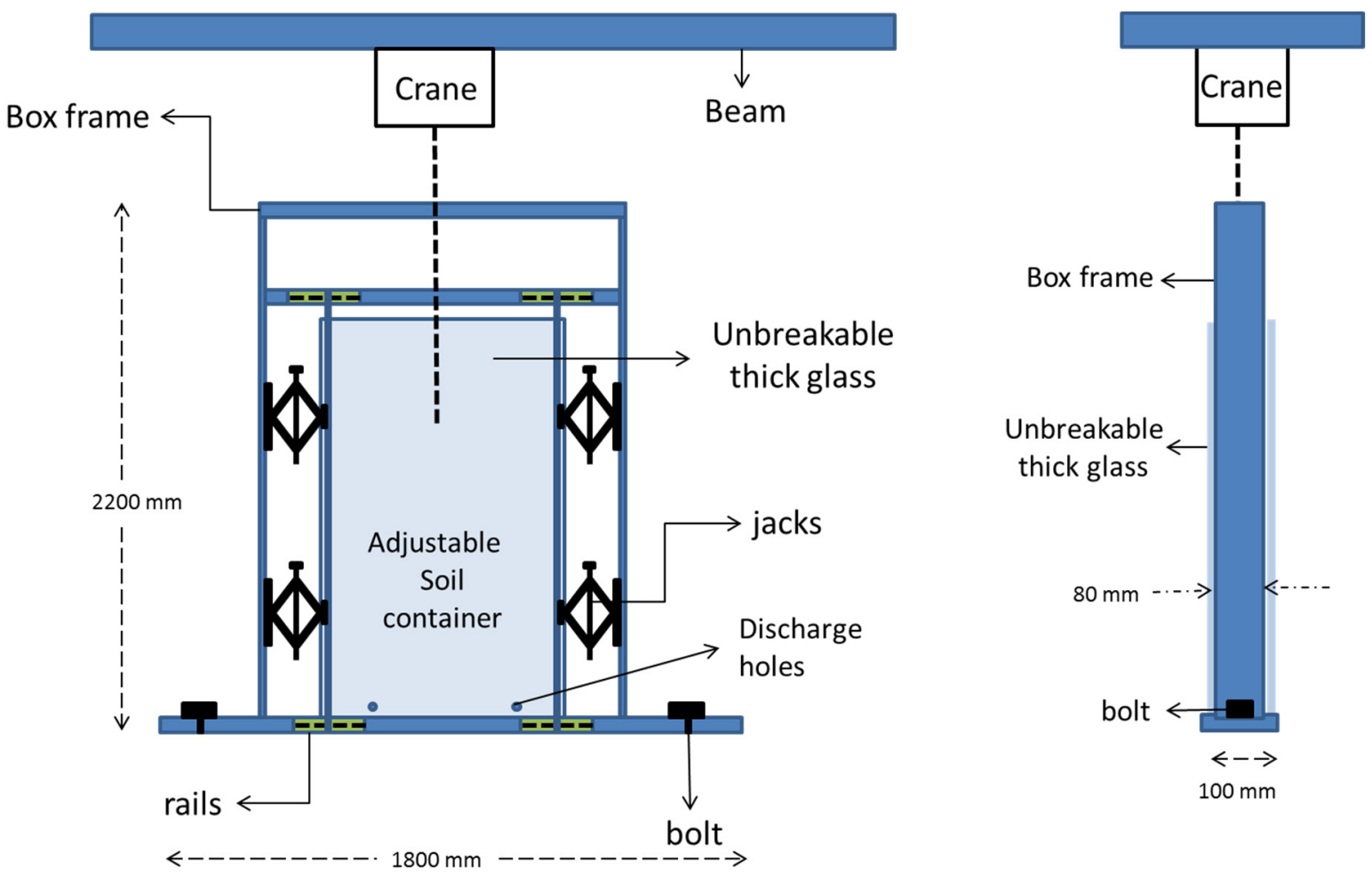

Fig. 3a Plane strain box.

Fig. 3b Photo of plane strain box.

\section{OPENING PLATE ANCHOR}

An innovated plate anchor called "opening plate anchor", which develops increasing bearing surface during uplift test, is introduced in this paper. The opening plate anchor is made of a rod and two plate wings, as shown in Figure 4. They can be closed and tightened the rod; therefore it can be driven or pushed in the soil axially. Then, the wings are unlocked and the springs between wings and rods, help the wings to be opened. In this research, the out-of-plane dimension of the anchor is $80 \mathrm{~mm}$ and the angle between wings is 120 degrees corresponds to anchor width of about $250 \mathrm{~mm}$.

In order to trace the anchor position in the soil during the test, 3 magnets were placed in anchor: two in wings and one in rod. Then, 3 other magnets were placed on the glass corresponding to magnet positions in anchor. Magnets movement on the glass shows anchor movement in the soil; therefore during the uplift test, the anchor position and its opening pattern are visible. The opening plate anchor is depicted in Figure 4. 


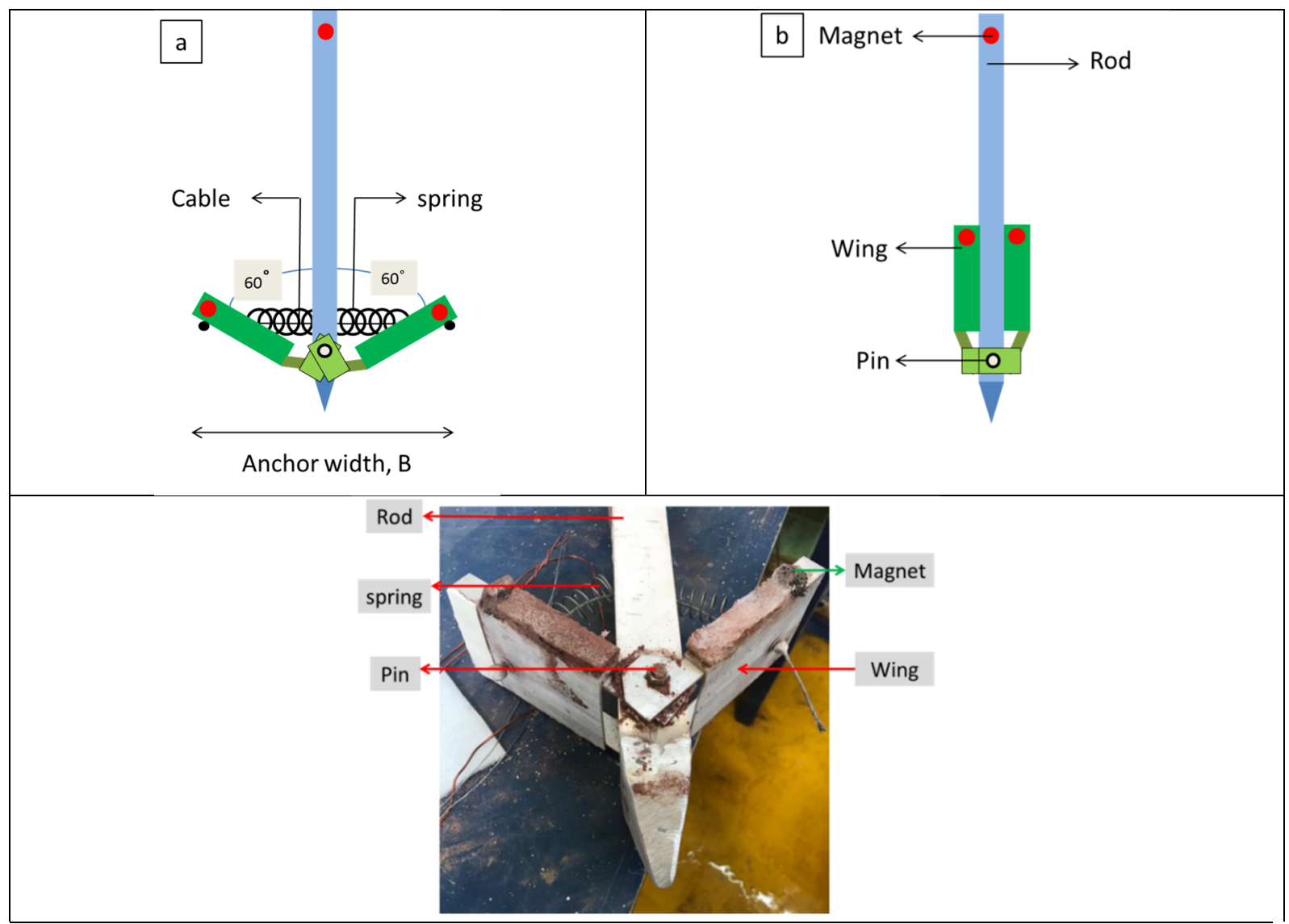

Fig. 4 Opening plate anchor.

a) Unlocked opening plate anchor; b) Locked opening plate anchor; c) Photo of opening plate anchor

\section{SOIL PROPERTIES}

In this research, Firoozkooh sand 161 was implemented. Typical sand properties are presented in Table 3. The friction angle is $32^{\circ}$, measured in direct shear test in accordance with ASTM D3080. The dry unit weight varied from $\gamma_{\mathrm{dmin}}=13.33 \mathrm{kN} / \mathrm{m}^{3}$ to $\gamma_{\text {dmax }}=16.14 \mathrm{kN} / \mathrm{m}^{3}$. The sample dry unit weight was measured $15.34 \mathrm{kN} / \mathrm{m}^{3}$ by free falling from $1000 \mathrm{~mm}$ in accordance with ASTM D3080 corresponding to relative density of $75 \%$ (ASTM, 2011).

\section{SAMPLE PREPARATION}

The opening plate anchor was locked and located on a $50-\mathrm{mm}$ thick sand bed laid at the bottom of the box. The anchor rod was perpendicular to box bottom. Magnets were located on the glass, corresponding to anchor magnets. The upper sand layers were placed by pulverization and tamping. In order to observe a more accurate and visible sand deformation, a 10-mm thick colored sand layer was overlaid on each $100 \mathrm{~mm}$ sand layer, until reaching the desired height. Finally the anchor rod was connected to loading frame for uplifting. The anchor embedment depths, measured from pin of the wings to soil surface, were 500, 750, 1000 and $1250 \mathrm{~mm}$, corresponding to embedment ratio $(\mathrm{H} / \mathrm{B})$ of 2, 3, 4 and 5 respectively.

In order to investigate the effect of soil surface restriction on sand deformation around the opening plate anchor, two series of tests were performed: (1) free soil surface and (2) restricted soil surface. For restricting soil surface, two rigid plates were located on the soil surface and fixed with rigid steel columns to upper frame of the box. Prepared samples for both tests are shown in Figure 5.

\section{TEST PROCEDURE}

Test procedure consists of uplifting the opening anchor plate, taking photo of test area and acquiring pullout load and anchor displacement. The camera was located $700 \mathrm{~mm}$ away from the box. As the glass reflects the light, the camera was located in a dark room. After adjusting the light, the camera was set to take one frame per second. After that, the data acquisition system and camera started to work. Then anchor uplift test started. The uplifting rate was about $1 \mathrm{~mm} / \mathrm{second}$. The test procedure continued until the opening plate anchor reached the soil surface.

\section{ANALYSIS OF RESULTS \\ LOAD VERSUS DISPLACEMENT CURVE}

The load vs. displacement curves of opening plate anchor for both free and restricted soil surface are shown in Figure 6. All curves trends are similar. In order to describe the opening plate anchor behavior more precisely, only 2 curves $(\mathrm{H} / \mathrm{B}=3$, free and restricted soil surface) are shown in Figure 7 individually and divided in to 5 and 4 parts according to different parts in load-displacement curve, respectively. 
Table 3 Physical and geotechnical properties of sand used in the tests.

\begin{tabular}{lccccccccc}
\hline $\begin{array}{l}\text { Soil } \\
\text { parameter: }\end{array}$ & $\begin{array}{c}\text { Angle of } \\
\text { friction, } \varnothing \\
\text { (degree) }\end{array}$ & $\begin{array}{c}\text { Sample } \\
\text { dry unit } \\
\text { weight, } \\
\gamma_{d}\end{array}$ & $\begin{array}{c}\text { Minimum } \\
\text { void ratio, } \\
e_{\min }\end{array}$ & $\begin{array}{c}\text { Void } \\
\text { ratio, } \\
\left(\mathrm{kNm} \mathrm{m}^{3}\right)\end{array}$ & $\begin{array}{c}\text { Maximum } \\
\text { void ratio, } \\
e_{\max }\end{array}$ & $\begin{array}{c}\text { Relative } \\
\text { density, } \\
D_{R}(\%)\end{array}$ & $\begin{array}{c}\text { Effective } \\
\text { grain } \\
\text { size, } d_{10} \\
(\mathrm{~mm})\end{array}$ & $\begin{array}{c}\text { Uniformity } \\
\text { coefficient, } \\
C_{u}\end{array}$ & $\begin{array}{c}\text { Coefficient } \\
\text { of } \\
\text { curvature, } \\
C_{c}\end{array}$ \\
\hline Sand & 32 & 15.34 & 0.637 & 0.68 & 0.886 & 75 & 0.17 & 2.58 & 0.97 \\
\hline
\end{tabular}
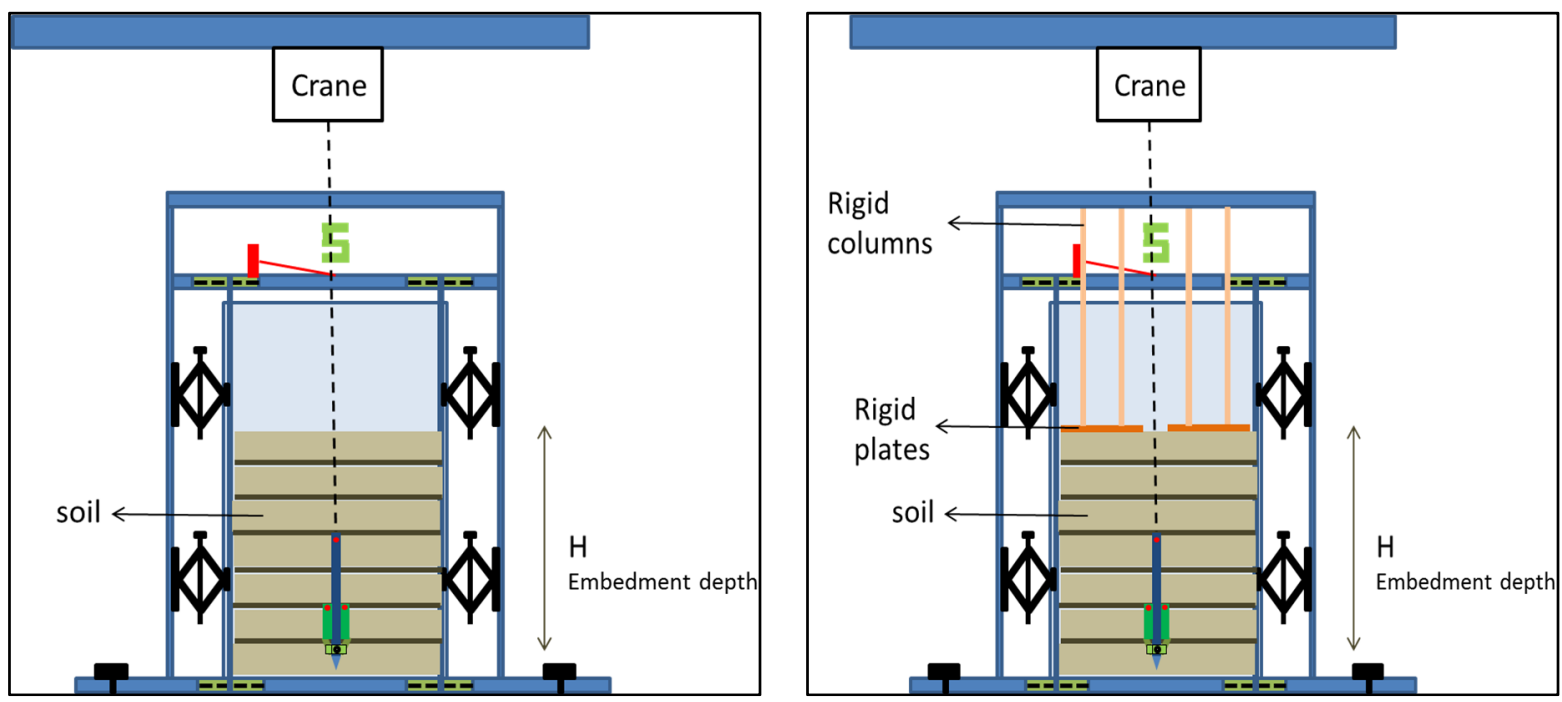

Fig. 5 Prepared sample of opening plate anchor for uplift test.
a) Free soil surface
b) Restricted soil surface

The uplift test starts from point $\mathrm{O}$. From $\mathrm{O}$ to $\mathrm{A}$, the anchor with closed wings, behave like an axial frictional anchor, which its shaft bearing mobilized due to initial upward movement.

In point $\mathrm{A}$, the anchor starts to move due to uplift resistance increase. The uplift resistance increases rapidly with displacement up to point $\mathrm{C}$. Before reaching point $C$, the anchor starts to open. From point $\mathrm{C}$ to point $\mathrm{D}$, the anchor uplift resistance decreases or stays constant with displacement. In all curves in point $\mathrm{D}$, the anchor is about $100^{\circ}$ opened. From point $\mathrm{D}$, the anchor uplift resistance increases rapidly up to point $\mathrm{E}$ that corresponds to maximum uplift resistance of the proposed anchor. In all curves the anchor was completely opened before reaching point $\mathrm{E}$.

\section{DISPLACEMENT FIELD AROUND AN UPLIFTING ANCHOR}

In order to improve the understanding the displacement field around the opening plate anchor and its opening magnitude during the uplift test, the displacement fields at different points determined in Figure 7, are presented (Fig. 8). As different embedment ratio (H/B) produces similar loaddisplacement curves in trend, the displacement field around the opening anchor in determined points $(\mathrm{O}, \mathrm{A}$, $\mathrm{C}, \mathrm{D}$ and $\mathrm{E})$ are presented for only one test $(\mathrm{H} / \mathrm{B}=3)$ and for both conditions (free soil surface and restricted soil surface) individually. The displacement field at the peak point (point E) for all tests are added at the end.

\section{A. FREE SOIL SURFACE}

The displacement field in point $\mathrm{A}$ is shown in Figure $8 \mathrm{a}$. According to Figure $7 \mathrm{a}$ in point $\mathrm{A}$, the opening anchor starts to move upward. As the displacements were not visible in real scale, the arrows are depicted 10 times bigger. It can be observed that a bulb above the anchor becomes compacted. As the anchor moves upward, a gap behind the anchor appears.

Point C corresponds to first peak in loaddisplacement curve and the anchor is opened about $60^{\circ}$. The displacement field in point $\mathrm{C}$ is presented in Figure $8 \mathrm{~b}$ in order to present the displacement field more visible, the arrows are magnified three times. It is indicated that the compacted bulb above the anchor becomes bigger and more compacted, and reaches the soil surface. As the soil surface is free, the compacted bulb moves up the soil surface and causes heave. Moreover, it can be observed that as the opening angle increases, the soil on the anchor escapes from the space between the rod and the wings and fills the created gap behind the anchor.

Figure 8c shows displacement field in point D, in which anchor is opened about $104^{\circ}$. It can be seen that in point $\mathrm{D}$ in comparison with point $\mathrm{C}$, the soil is more compacted and soil surface heave increases. As the anchor opens, the resistant surface extends, and the width of bearing increases too.

In point $\mathrm{E}$, the anchor uplift resistance reaches its maximum value. Displacement field corresponds to 


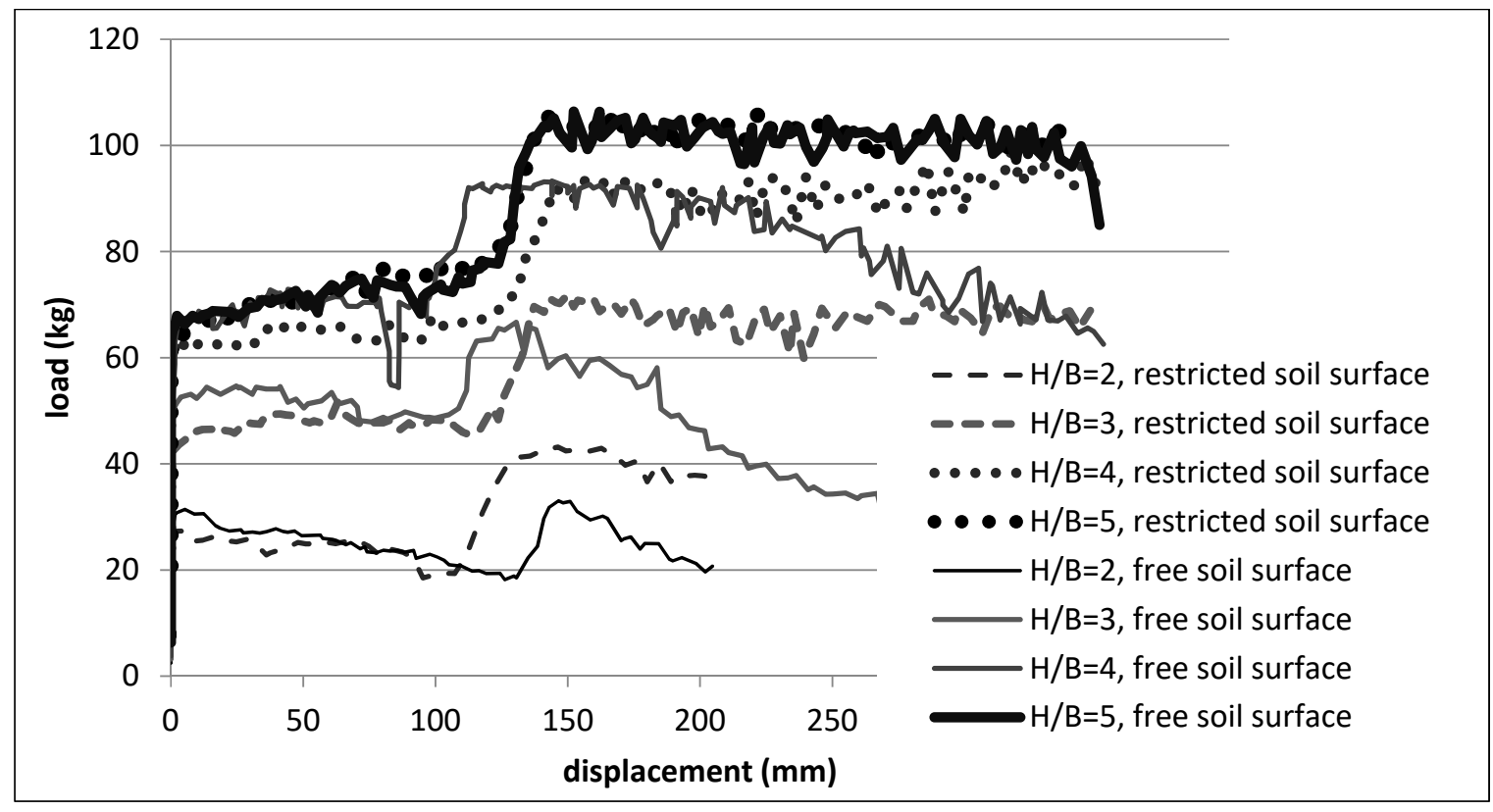

Fig. 6 Load versus displacement curve

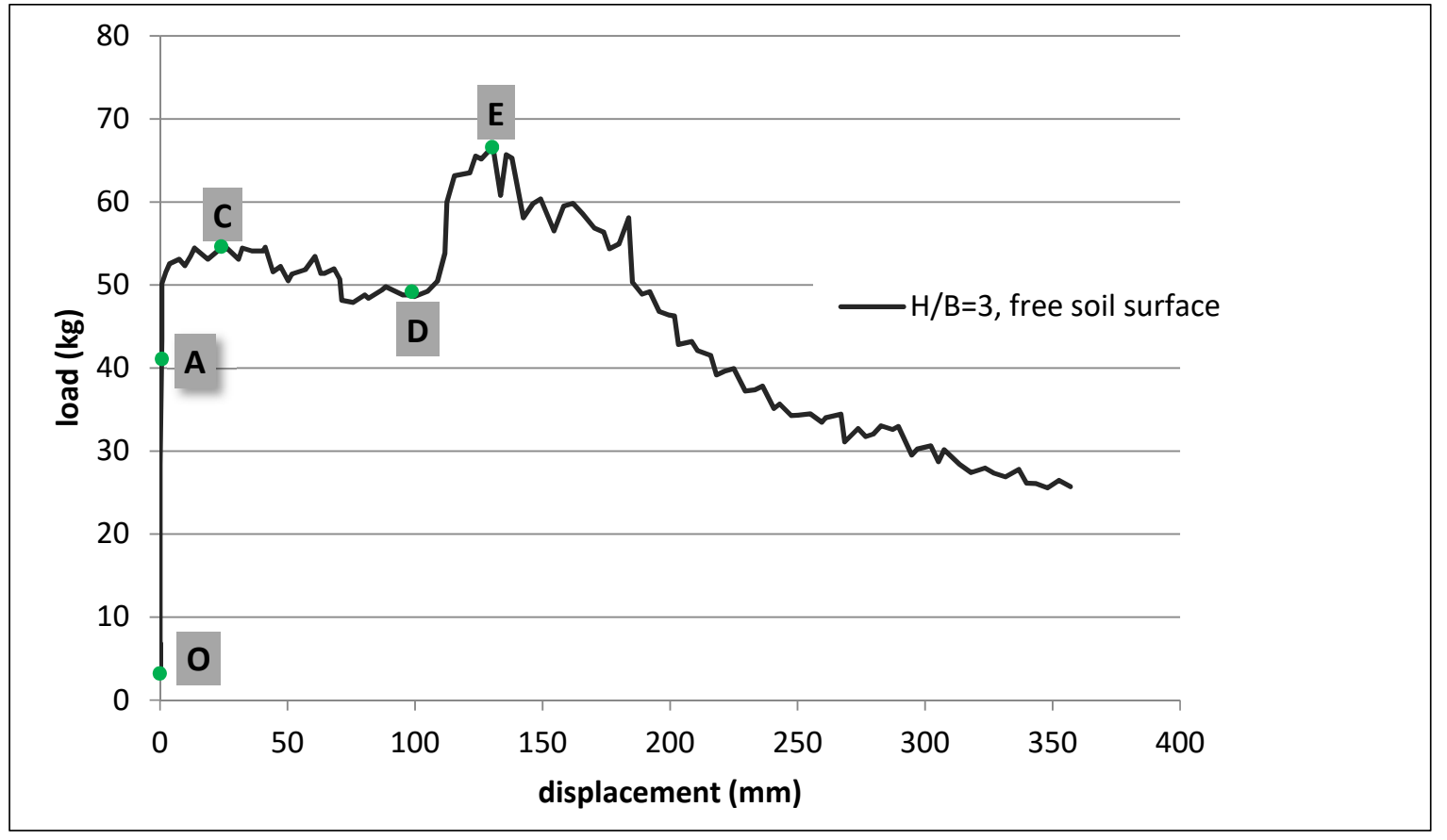

Fig. 7 a Load versus displacement curve of condition $H / B=3$, free soil surface.

point $\mathrm{E}$ is shown in Figure 8d. It is observed that the compacted block above the anchor and two triangular shear zones move upward. The soil surface displacement above the anchor and in middle increases. It is indicated that effect zone of anchor uplift includes a compacted block above the anchor and two triangular shear zones that reaches to the freesoil surface for embedment ratio (H/B) of 3 .

\section{B. RESTRICTED SOIL SURFACE}

Field displacement during uplift test on opening anchor with embedment ratio of three in restricted soil surface condition is shown in Figure 9. According to
Figure $7 \mathrm{~b}$ in point $\mathrm{A}$, the anchor starts to move upward. Figure 9a shows displacement field in point A. In order to present a more visible displacement field, the arrows are depicted with magnification ratio of five. It is observed that a block in a bulb above the anchor becomes compacted. Figure $9 \mathrm{~b}$ depicts the displacement field in point $\mathrm{D}$, where the anchor is opened about $105^{\circ}$. It can be observed that wings open and the block above the anchor becomes more compacted. But the compacted bulb does not reach the restricted soil surface. Figure 9c shows the displacement field in point $\mathrm{E}$, in which the anchor uplift resistance reaches its maximum value. 


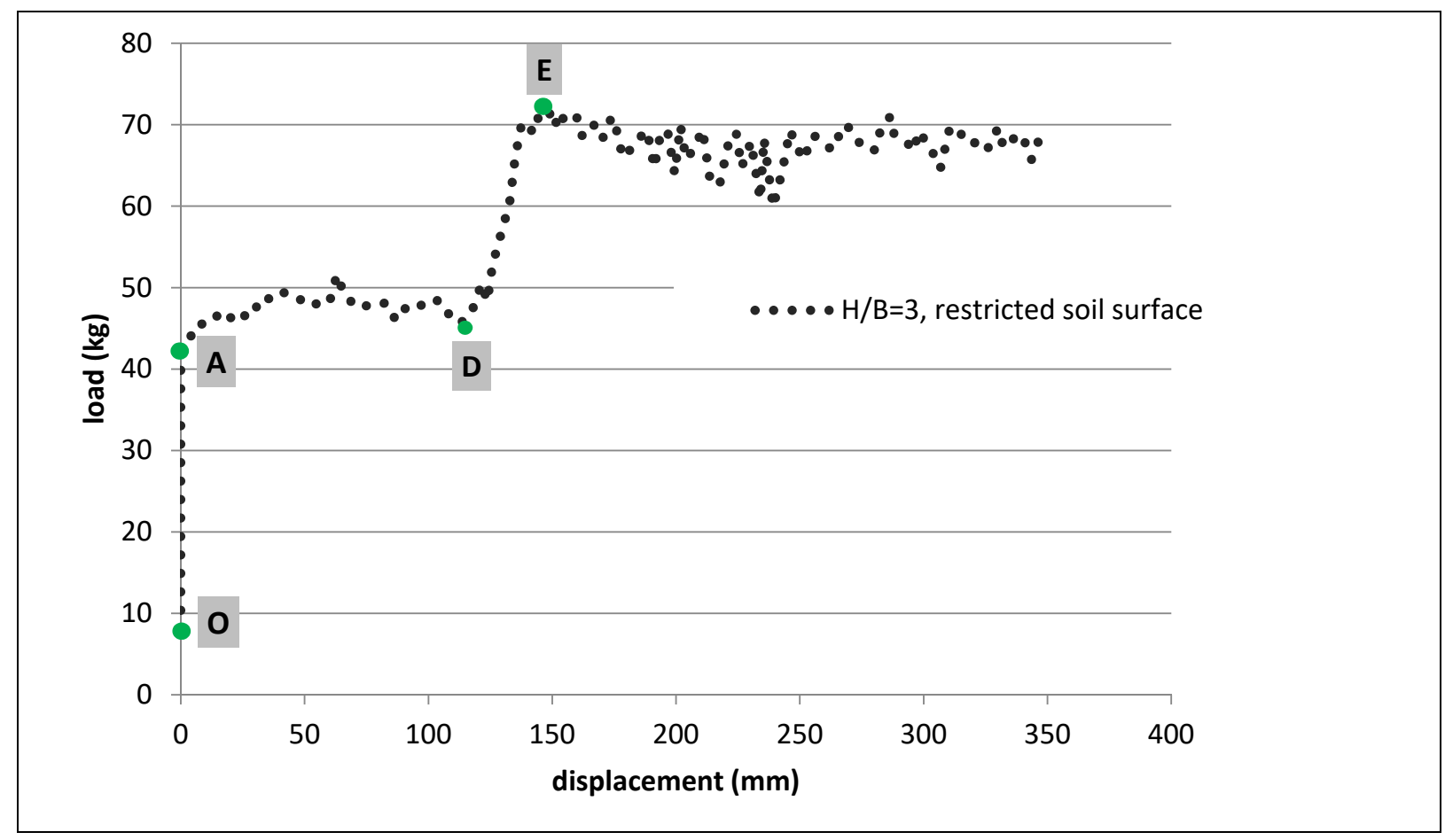

Fig. 7 b Load versus displacement curve of condition $H / B=3$, restricted soil surface.

According to Figure 9c, the compacted bulb height increases, although it does not reach the restricted surface. On the opposition of free soil surface condition, in restricted soil surface, the effect zone of opening plate anchor placed in embedment depth of $3 \mathrm{~B}$ in sand, does not reach the soil surface and is similar to a punching shear failure mode.

\section{DISPLACEMENT FIELD AT THE PEAK POINT (POINT E)}

Displacement field at the peak point denoted by point $\mathrm{E}$ for different embedment ratios for free soil surface condition and restricted soil condition are shown in Figure 10 and Figure 11, respectively.

As shown in Figure 10, in free soil surface condition for shallow anchors $(\mathrm{H} / \mathrm{B}=2,3)$ effect zone reaches the soil surface, while for deep anchors $(\mathrm{H} / \mathrm{B}=4,5)$ effect zone does not reach the soil surface. For shallow anchors, as embedment ratio increases, soil surface upward movement increases. For deep anchors, as embedment ratio increases, the height of influence zone decreases and its width increases.

In Figure11, in restricted soil surface condition, the shallowest anchor $(\mathrm{H} / \mathrm{B}=2)$ effect zone crosses the soil surface. After that, as embedment ratio increases, the effect zone does not reach the soil surface and the failure surface is similar to shear punch surface. For shear punch failures $(\mathrm{H} / \mathrm{B}=3,4,5)$ as embedment ratio increase, the width of effect zone increases and its height decreases. It can be concluded that restricting the soil surface can be equal to embedding the anchor deeper.

\section{SHEAR STRAIN FIELD AROUND AN UPLIFTING ANCHOR}

The soil strains can be deduced from soil deformation. The failure surface can be approximately investigated by recognizing the points with maximum shear strain values. Other researchers have performed this method to identify the failure surfaces (Liu et al., 2011; Yamamoto and Kusuda, 2001).

Two significantly different failure surfaces are observed for two anchors with the same embedment depth, but different soil surface conditions, as shown in Figures 12 (free soil surface) and 13 (restricted soil surface). In free soil surface condition, two curve failure surfaces are formed that extend to soil surface. However, in restricted soil surface, a shear zone similar to the bulb observed in the shear strain fields. The failure surfaces form a cavity in the soil.

It can be concluded that effect zone observed from the displacement field are approximately similar to failure surfaces observed from shear strain field, however the width of shear strain zones are less than width of deformation effect zone.

\section{CONCLUSIONS}

A new mechanical anchor is introduced in the proposed paper. In order to recognize the behavior of innovated anchor, two series of uplift tests in a plane strain box were implemented and the effects of embedment depth and soil surface restriction on soil deformation around the anchor were studied by using PIV as image processing system.

- It can be concluded that, in free soil surface for shallow anchors $(H / B=2,3)$ the failure surface is similar to a curve, as Mariupolski (1965) reported 


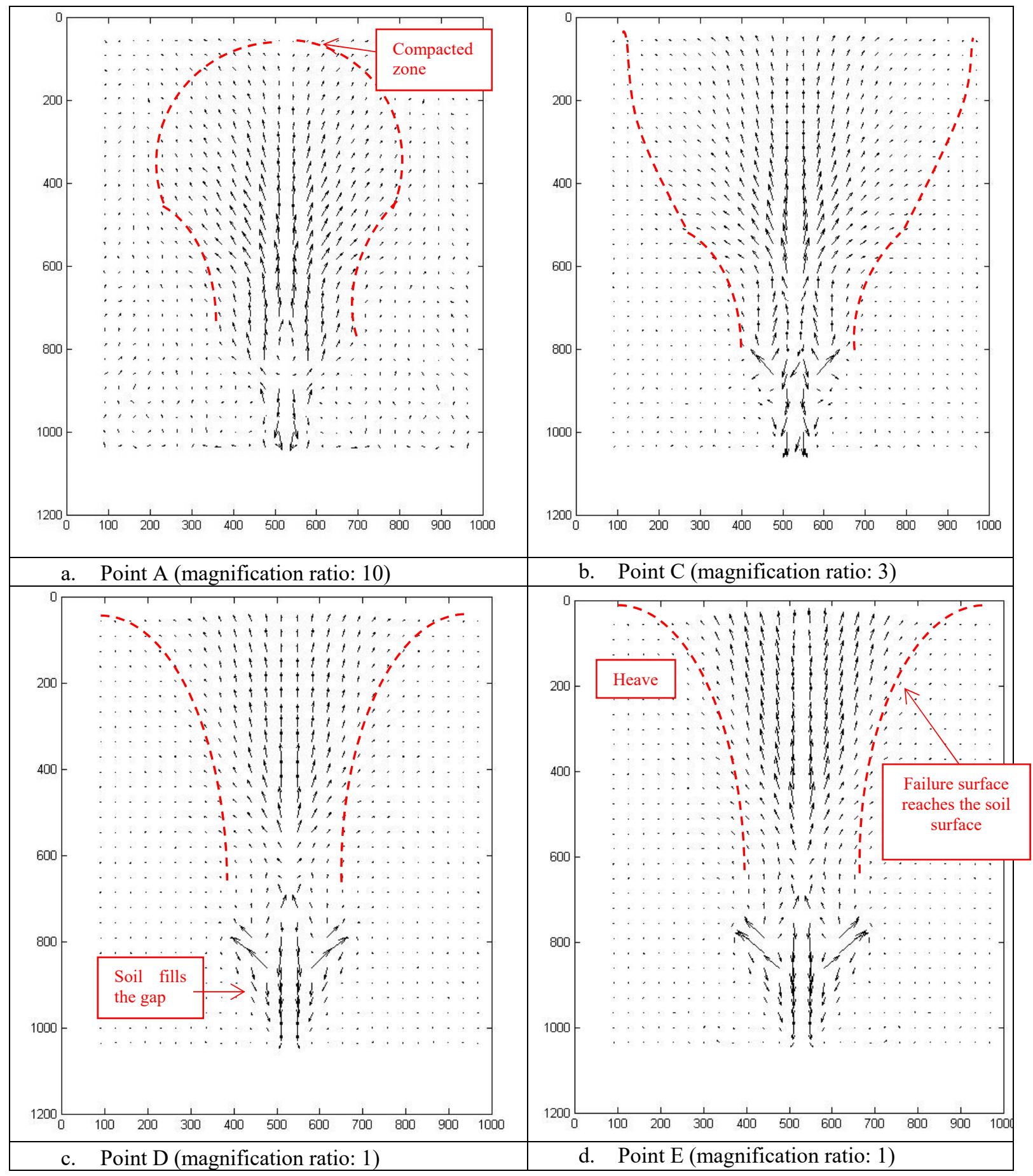

Fig. 8 Displacement field around opening plate anchor $(\mathrm{H} / \mathrm{B}=3$, free soil surface $)$ in determined points.

for shallow anchors. In this condition, failure surface crosses the soil surface.

- In free soil surface as embedment ratio increases $(\mathrm{H} / \mathrm{B}=4,5)$ and anchor acts as deep anchor, the failure surface dose not reach the soil surface and is similar to shear punch failure.

- For restricted soil condition, the failure surface of the shallowest anchor $(\mathrm{H} / \mathrm{B}=2)$ reaches the soil surface and after that, as embedment ratio increase $(\mathrm{H} / \mathrm{B}=3,4$ and 5$)$, the anchor's behavior becomes similar to deep anchor and the punching shear surface is observed. In other words, in this condition the failure surface does not extend to soil surface.

- For both soil conditions (free and restricted soil surface), for deep anchors, as embedment ratio increases, the height of influence zone decreases and its width increases."

- It can be concluded that effect zone observed from the displacement field are similar to failure surfaces observed from shear strain field, however the width of shear strain zones is less than width of deformation effect zone. 


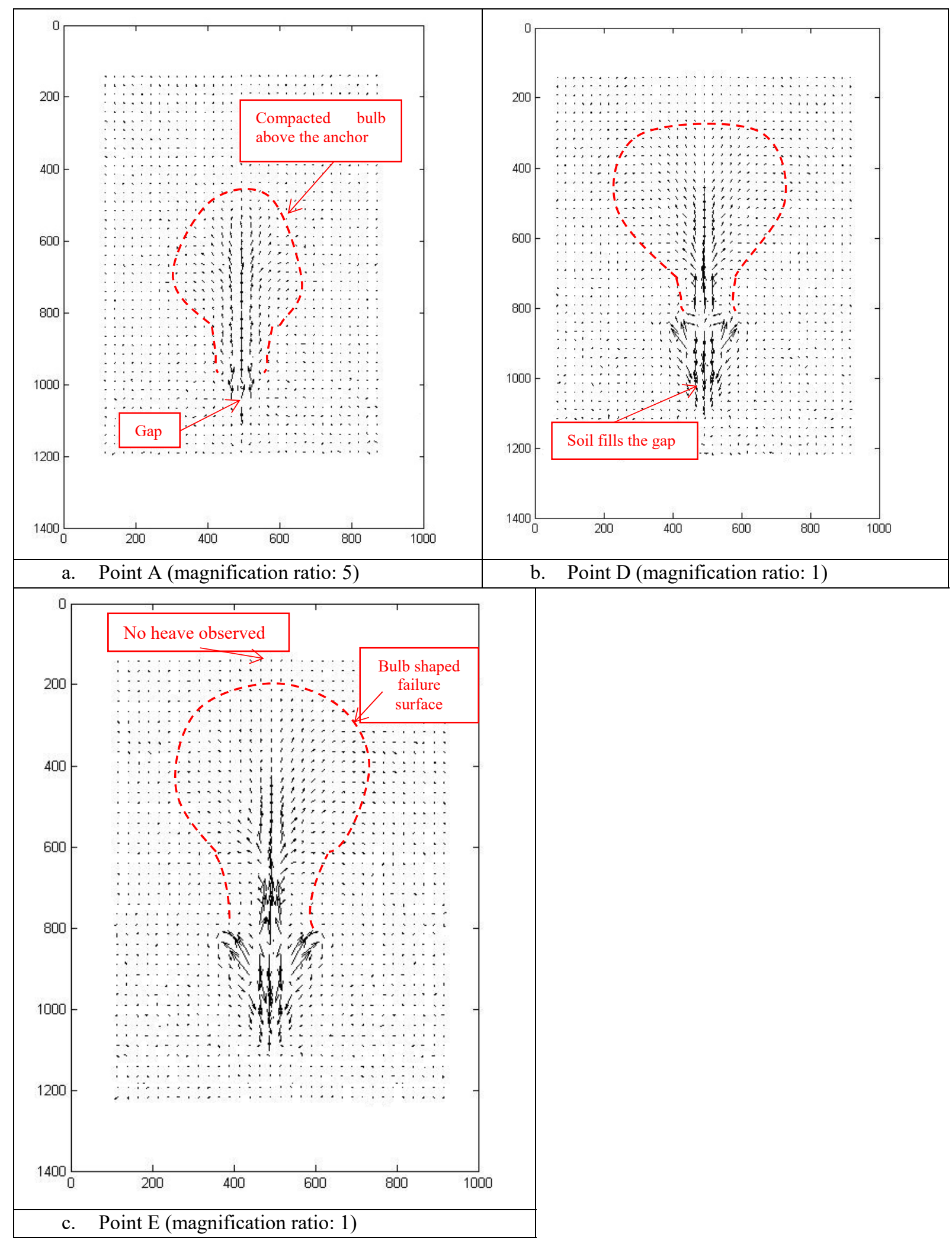

Fig.9 Displacement field around opening plate anchor $(\mathrm{H} / \mathrm{B}=3$, restricted soil surface $)$ in determined points.

\section{REFERENCES}

ASTM, D.: 2011, Standard test method for direct shear test of soils under consolidated drained conditions. D3080/D3080M.
Baker, W.H. and Konder, R.L.: 1966, Pullout load capacity of a circular earth anchor buried in sand. Highway Research Record, 108.

Ball, A.: 1961, The resistance to breaking-out of mushroom foundations for pylons. Paper presented at the 5 th Int. Conf. on SMFE. 


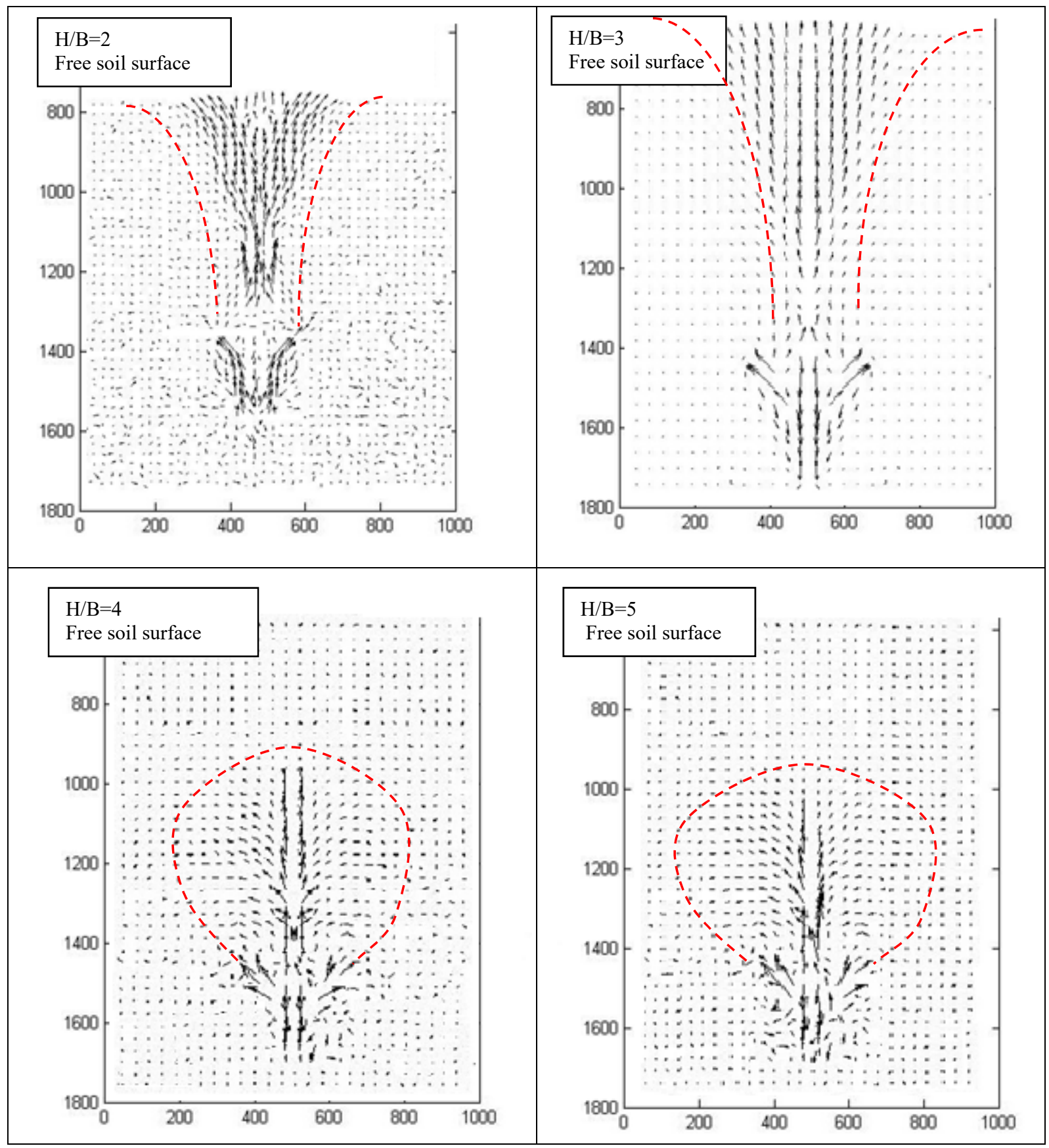

Fig. 10 Displacement field at point E around opening plate anchor for free soil surface condition

Chattopadhyay, B. and Pise, P.: 1986, Breakout resistance of horizontal anchors in sand. Soils and Foundations, 26, No. 4, 16-22. DOI: 10.3208/sandf1972.26.4 16

Das, B.M. and Shukla, S.K.: 2013, Earth anchors. J. Ross Publishing.

Dickin, E.A. and Laman, M.: 2007, Uplift response of strip anchors in cohesionless soil. Advances in Engineering Software, 38, No. 8, 618-625.

DOI: 10.1016/j.advengsoft.2006.08.041

Dickin, E.A.: 1988, Uplift behavior of horizontal anchor plates in sand. Journal of Geotechnical Engineering, 114 , No. $11,1300-1317$.

DOI: 10.1061/(ASCE)0733-9410(1988)114:11(1300)
Dickin, E.A.: 1994, Uplift resistance of buried pipelines in sand. Soils and Foundations, 34, No. 2, 41-48. DOI: $10.3208 /$ sandf1972.34.2 41

Duan, X.-f., Wang, Y.-z. and Yuan, X.-m.: 2018, State-ofthe-art Review of Particle Image Velocimetry (PIV) in Geotechnical Engineering, DEStech Transactions on Computer Science and Engineering. DOI: $10.12783 / \mathrm{dtcse} / \mathrm{ammms} 2018 / 27324$

Frydman, S. and Shaham, I.: 1989, Pullout capacity of slab anchors in sand. Canadian Geotechnical Journal, 26, No. 3, 385-400. DOI: 10.1139/t89-053

Ganesh, R. and Sahoo, J. P.: 2016, Uplift capacity of horizontal strip plate anchors adjacent to slopes 


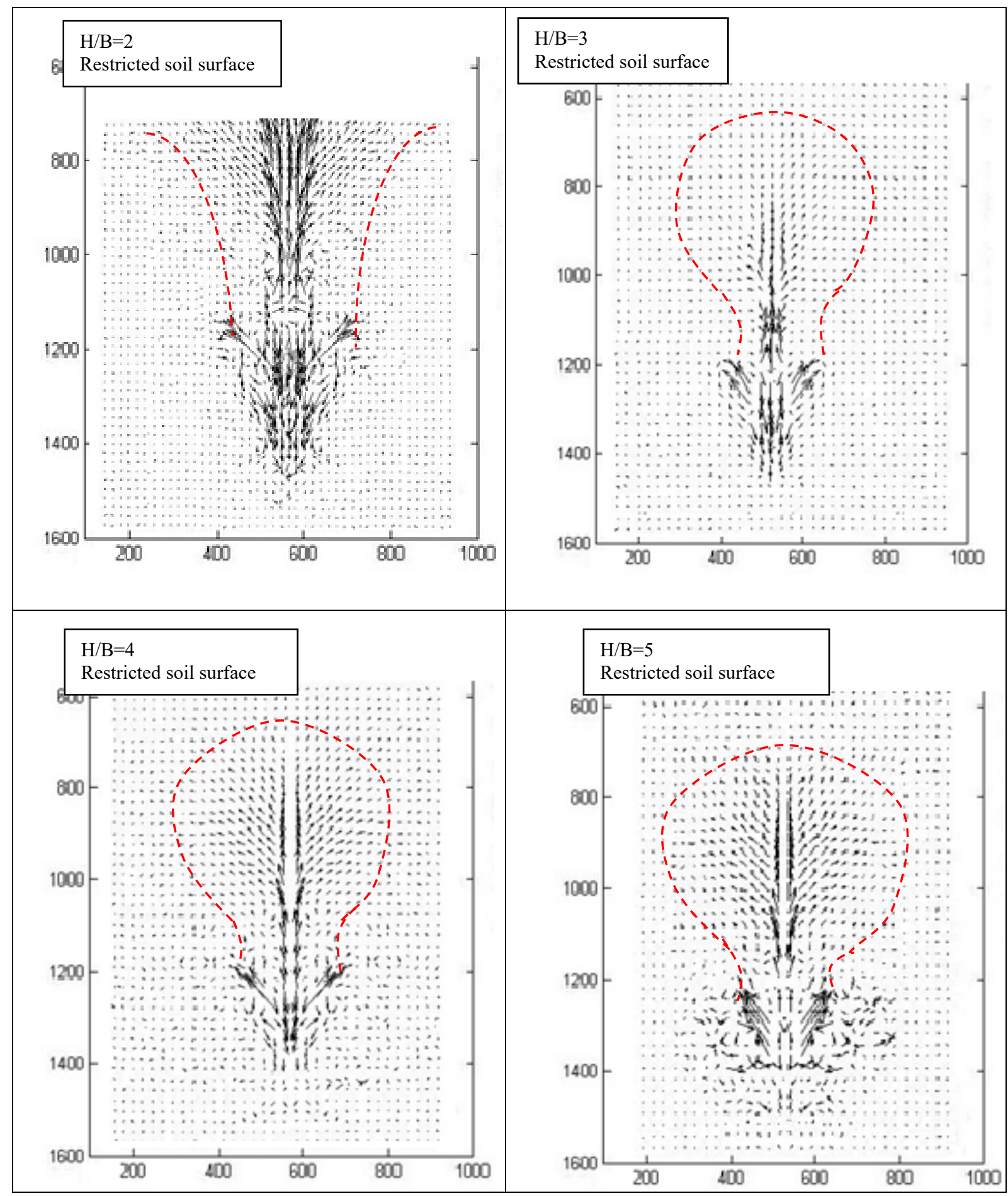

Fig. 11 Displacement field at point E around opening plate anchor for restricted soil surface condition.

considering seismic loadings. Soils and Foundations, 56, No. 6, 998-1007.

DOI: 10.1016/j.sandf.2016.11.005

Ilamparuthi, K., Dickin, E.A. and Muthukrisnaiah, K.: 2002, Experimental investigation of the uplift behaviour of circular plate anchors embedded in sand. Canadian Geotechnical Journal, 39, No. 3, 648-664. DOI: $10.1139 / \mathrm{t} 02-005$

Keskin, M.S.: 2015, Model studies of uplift capacity behavior of square plate anchors in geogrid-reinforced sand. Geomechanics and Engineering, 8, No. 4, 595613. DOI: $10.12898 /$ gae2015.8.4.595
Krishnaswamy, N. and Parashar, S.: 1994, Uplift behaviour of plate anchors with geosynthetics. Geotextiles and Geomembranes, 13, No. 2, 67-89.

DOI: $10.1016 / 0266-1144(94) 90040-X$

Kumar, J. and Bhoi, M.K.: 2009, Vertical uplift capacity of equally spaced multiple strip anchors in sand. Geotechnical and Geological Engineering, 27, No. 3, 461-472. DOI: $10.1007 / \mathrm{s} 10706-008-9247-7$

Liu, J., Liu, M. and Zhu, Z.: 2011, Sand deformation around an uplift plate anchor. Journal of Geotechnical and Geoenvironmental Engineering, 138, No. 6, 728-737. DOI: 10.1061/(ASCE)GT.1943-5606.0000633 


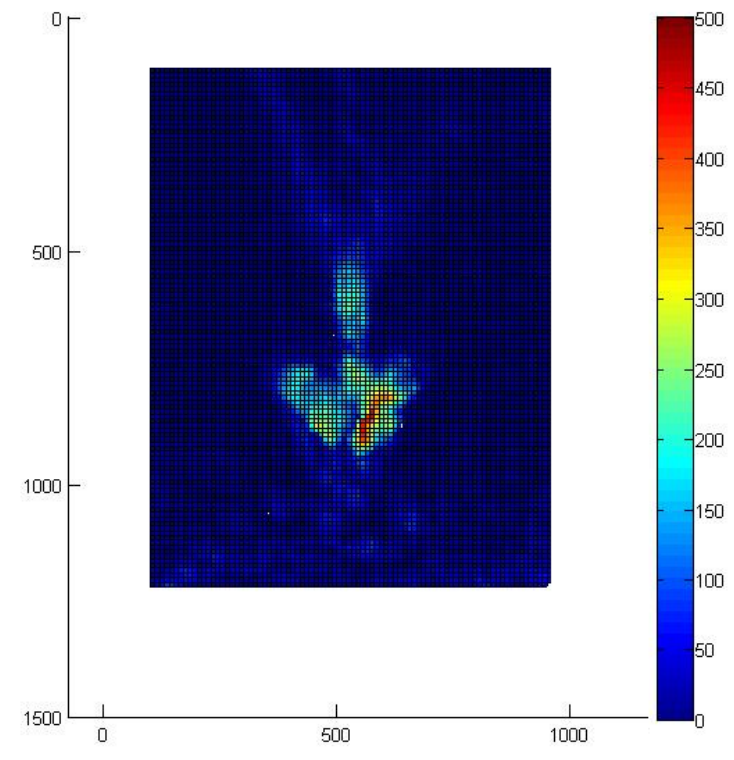

Fig. 12 Shear strain field of condition $H / B=3$, free soil surface.

MacDonald, H.F.: 1963, Uplift resistance of caisson piles in sand. Nova Scotia Technical College.

Majer, J.: 1955, The estimation of train foundations. Osterreichische Bauzeitschrift, 10, No. 5, 85-90, (in German).

Mariupol'skii, L.G.: 1965, The bearing capacity of anchor foundations. Soil Mechanics and Foundation Engineering, 2, No. 1, 26-32.

Matsuo, M.: 1968, Study on the uplift resistance of footing (II). Soils and foundations, 8, No. 1, 18-48.

Meyerhof, G.G. and Adams, J.I.: 1968, The ultimate uplift capacity of foundations. Canadian Geotechnical Journal, 5, No. 4, 225-244. DOI: 10.1139/t68-024

Mors, H.: 1959, The behavior of mat foundations subjected to tensile forces. Bautechnik, 36, No. 10, 367-378, (in German).

Murray, E., and Geddes, J.: 1989, Resistance of passive inclined anchors in cohesionless medium, Geotechnique, 39, No. 3, 417-431. DOI: 10.1680/geot.1989.39.3.417

Rahimi, M., Tafreshi, S.M., Leshchinsky, B. and Dawson, A.: 2018, Experimental and numerical investigation of the uplift capacity of plate anchors in geocellreinforced sand. Geotextiles and Geomembranes, 46, No. 6, 801-816.

DOI: 10.1016/j.geotexmem.2018.07.010

Rhadilkar, B., Paradkar, A. and Golait, Y.: 1971, Study of rupture surface and ultimate resistance of anchor foundations. Paper presented at the Fourth Asian Regional Conf Proc.

Rowe, R.K. and Davis, E.H.: 1982, The behaviour of anchor plates in sand. Geotechnique, 32, No. 1, 25-41. DOI: 10.1680/geot.1982.32.1.25

Sabatini, P., Pass, D. and Bachus, R.C.: 1999, Ground anchors and anchored systems. United States, Federal Highway Administration. Office of Bridge Technology.

Sakai, T. and Tanaka, T. 1998, Scale effect of a shallow circular anchor in dense sand. Soils and Foundations, 38, No. 2, 93-99. DOI: 10.3208/sandf.38.2_93

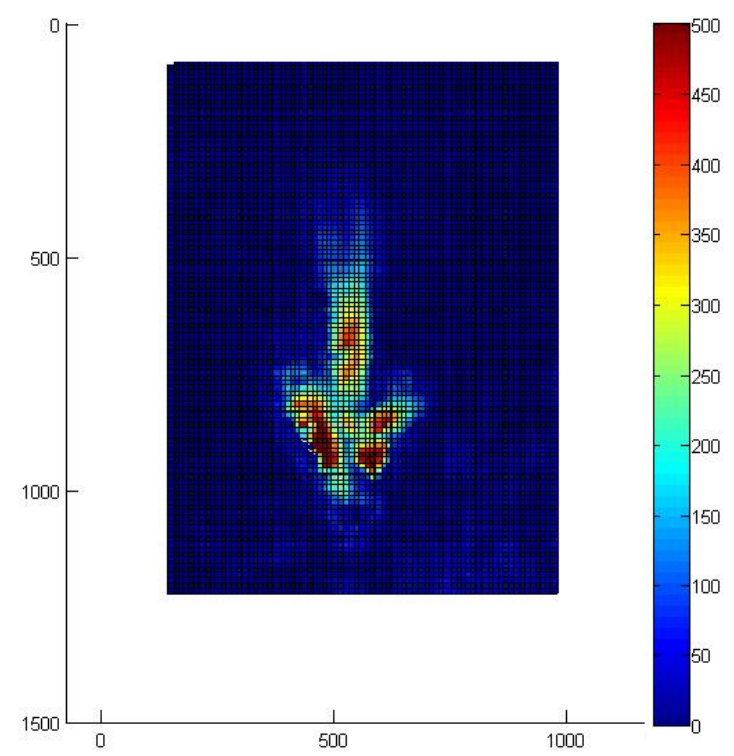

Fig. 13 Shear strain field of condition $H / B=3$, restricted soil surface.

Sergeev, I. and Savchenko, F.: 1972, Experimental investigations of soil pressure on the surface of an anchor plate. Soil Mechanics and Foundation Engineering, 9, No. 5, 298-300.

Veesaert, C. and Clemence, S.: 1977, Dynamic pullout resistance of anchors. Paper presented at the International Symposium on Soil-Structure Interaction, Rourkee, India.

Yamamoto, K. and Kusuda, K.: 2001, Failure mechanisms and bearing capacities of reinforced foundations. Geotextiles and Geomembranes, 19, No. 3, 127-162. DOI: $10.10 .16 / \mathrm{S} 0266-1144(01) 00003-6$

\section{APPENDIX I - NOTATION}

The following symbols are used in this paper:

\begin{tabular}{cl}
\hline Parameter & Description \\
\hline$B$ & Width of anchor \\
$C_{c}$ & Coefficient of curvature \\
$C_{u}$ & Uniformity coefficient \\
$d_{10}$ & Effective grain size $(\mathrm{mm})$ \\
$D_{R}$ & Relative density $(\%)$ \\
$H$ & Embedment depth of anchor $(\mathrm{mm})$ \\
$L$ & Length of rectangular anchor $(\mathrm{mm})$ \\
$L / B$ & Aspect ratio \\
$N_{q}$ & Breakout factor \\
$P$ & Pullout capacity (kg) \\
$t$ & Anchor thickness (mm) \\
$\gamma_{d}$ & Sample dry unit weight $\left(\mathrm{kN} / \mathrm{m}^{3}\right)$ \\
$\gamma_{d_{\max }}$ & Maximum dry unit weight $\left(\mathrm{kN} / \mathrm{m}^{3}\right)$ \\
$\gamma_{d_{\min }}$ & Minimum dry unit weight $\left(\mathrm{kN} / \mathrm{m}^{3}\right)$ \\
$\varphi$ & Angle of friction (degree) \\
$\theta$ & Angle between soil surface and \\
& failure surface (degree) \\
\hline
\end{tabular}

